\title{
Ketidaklaziman Dalam Novel Tarian Dua Wajah Karya S. Prasetyo Utomo: Sebuah Kajian Religiusitas
}

\author{
Rokhyanto \\ Pendidikan Bahasa dan Sastra Indonesia \\ IKIP Budi Utomo Malang \\ lohpola91@gmail.com
}

\begin{abstract}
Abstrak: Penelitian ini bertujuan untuk mengkaji nilai-nilai spiritualitas dari novel Tarian Dua Wajah karya S. Prasetyo Utomo. Novel ini memuat tentang kisah seorang anak manusia yang dilhirkan, tetapi diasuh oleh pamannya, tetapi istri kakak dari ayahnya sungguh menyiksa, sehingga mulai menginjak dewasa dia mencari guru spiritual agar bisa menjadi orang yang berguna. Penelitian ini menggunakan metode penelitian deskriptif kualitatif. Sumber data dalam penelitian ini yakni teks novel dengan judul Tarian Dua Wajah yang ditulis oleh S. Prasetyo Utomo. Identitas sumber data ialah judul novel Tarian Dua Wajah, pengarang S. Prasetyo Utomo, jumlah halaman 258, penerbit PT Pustaka Alvabet Tangerang Selatan, Cetakan 1 Juni 2016. Setelah semua data terkumpul, maka dianalisis menggunakan analisis data yang terdiri dari (1) reduksi data, (2) penyajian data, dan (3) penarikan kesimpulan. Hasil penelitian menunjukan bahwa tokoh dilukiskan sebagai pribadi yang teguh pendirian, agamis, pendiam, dan memegang teguh agamanya Allah.
\end{abstract}

\section{Kata kunci: novel, spiritualitas, karya sastra}

\begin{abstract}
This study aims to examine the values of spirituality from the novel The two-faced dance by S. Prasetyo Utomo. The Novel contains the story of a man's child who is cleansed, but is taken care of by his uncle, but the wife of his father is really agonizing, so he begins to mature he seeks a spiritual teacher in order to become a useful person. This research uses qualitative descriptive research methods. The source of the data in this research is the novel text with the title of Dua face dance written by S. Prasetyo Utomo. The identity of the data source is the novel title of Dance Two Faces, author S. Prasetyo Utomo, number of pages 258, publisher of PT Pustaka Alvabet South Tangerang, prints June 1, 2016. Once all data is collected, it is analyzed using data analysis consisting of (1) data reduction, (2) data presentation, and (3) withdrawal of conclusions. The results show that the character is portrayed as a firm personage, Agamis, reserved, and holds the true religion of God.
\end{abstract}

Keywords: Novels, spirituality, literary 


\section{PENDAHULUAN}

Sastra dan nilai religi bagian dari fenomena sosial yang saling melengkapi dalam kemandirian, keduanya sebagai sesuatu yang ekstensial. Sebagai bentuk seni, kehadiran sastra bersumber dari kehidupan yang bertata nilai, dan pada giliran yang lain sastra juga akan memberikan sumbangan bagi terbentuknya tata nilai. Hal itu terjadi karena setiap cipta seni yang dibuat dengan kesungguhan tentu mengandung keterikatan yang kuat dengan kehidupan, karena manusia pelahir cipta seni tersebut adalah bagian dari kehidupan itu sendiri. Sastra sebagai produk kehidupan, mengandung nilai-nilai sosial, falsafi, religi dan sebagainya, baik yang bertolak dari pengungkapan kembali maupun penyodoran

konsep baru.

Sastra yang multi dimensi ini dapat dikaji tentang nilai-nilai spiritualitas dari novel Tarian Dua Wajah karya S. Prasetyo Utomo. Novel ini memuat tentang kisah seorang anak manusia yang dialhirkan, tetapi diasuh oleh pamannya, tetapi istri kakak dari ayahnya sungguh menyiksa, sehingga mulai menginjak dewasa dia mencari guru spiritual agar bisa menjadi orang yang berguna.

Dia dilukiskan salah satu tokoh yang teguh pendirian, agamis, pendiam, dan memegang teguh agamanya Allah. Novel ini tampaknya telah berhasil merebut sisi hati penikmatnya, hal ini dapat dilihat dari banyaknya komentar/tanggapan yang menyambut baik kehadiran novel Tarian Dua Wajah. Dalam novel ini sangat kental dengan nuansa seni tari dengan ditumbuhi agamis, sehingga yang sangat mendukung isi novel dan berbobot kandungan di dalamnya untuk mengukuhkan novel ini sebagai media dakwah.

Banyak hikmah yang dapat dipetik, terutama mengenai bagaimana berinteraksi dengan sesama manusia, baik muslim maupun non muslim, mukhrin dan bukan mukhrim. Tersusun dalam bahasa yang indah dan halus. Setiap kejadian tersususn secara kompak, satu kejadian akan berhubungan dengan kejadian selanjutnya. Nyaris tidak ada kejadian 
yang sia-sia. Setiap bab-nya menghadirkan kejutan-kejutan tersendiri, hingga pembaca dibuat penasaran untuk terus mengikuti kisahnya dari awal hingga akhir dan banyak lagi komentar lain dari para penggemar novel Tarian Dua Wajah.

Novel Tarian Dua Wajah ini karya S. Prasetyo Utomo ini termasuk sastra modern. Menurut Saryono (2009:69) sastra modern memang bukan semata-mata penyimpan dan perawat norma-norma etis dan moral, tetapi tidak berarti hampa nilai etis dan moral. Pada dasarnya, setiap karya sastra yang baik, baik klasik atau lama maupun modern, selalu mengemban pesan-pesan etis dan moral, sehingga sastra modern yang baik selalu menyuarakan himbauan-himbauan etis dan moral. Hal tersebut di atas yang membuat peneliti berkeinginan mengungkap tentang nilai moral yang disisipkan oleh S. Prasetyo Utomo dalam novel Tarian Dua Wajah. Selain itu, sepengetahuan peneliti belum ada yang menganalisis novel Tarian Dua Wajah terutama dari segi nilai spiritualitas, khususnya nilai-nilai sosok tokoh yang baik dan sosok tokoh yang berkarakter baik. Akan tetapi, ada juga tokoh yang berkarakter buruk, tetapi menyadari akan kesalahan itu semua akhirnya menjadi tobat.

Permasalahan di atas dapat di spesifikan berikut ini: bagaimanakah kondisi sebelum tokoh melaksanakan spiritualitas dalam Novel Tarian Dua Wajah Karya S. Prasetyo Utomo? dan bagaimanakah kondisi akhir tokoh melaksanakan spiritualitas dalam Novel Tarian Dua Wajah Karya S. Prasetyo Utomo?

Tujuan tulisan ini sebagai berikut: ingin mengetahui deskripsi secara rinci kondisi sebelum tokoh melaksanakn spiritualitas dalam Novel Tarian Dua Wajah Karya S. Prasetyo Utomo; ingin mengetahui deskripsi secara rinci kondisi akhir tokoh melaksanakan spiritualitas dalam Novel Tarian Dua Wajah Karya S. Prasetyo Utomo. Manfaat hasil tulisan ini diharapkan dapat dijadikan sebagai bahan pelengkap landasan teori bagi peneliti yang tertarik untuk lebih mendalami penelitian tentang sastra dan dapat dijadikan sebagai acuan serta landasan tulisan sejenis. 
Hasil tulisan ini ini juga dapat ditiru cara-cara aplikatif teori spiritual-religius sebagai bahan untuk mengadakan penelitian yang sejenis, sehingga memudahkannya untuk mengadakan penelitian lebih lanjut.

Bagi pengembang ilmu pengetahuan, kiranya hasil penelitian ini dapat memperkaya hasil penelitian bidang sastra, khususnya religiusitas dari spiritual novel. Selain itu, dapat menumbuhkan minat baca para peminat sastra dan dapat memperkaya acuan bagi peneliti-peneliti lain bidang yang sejenis.

\section{METODE PENELITIAN}

Penelitian ini menggunakan pendekatan kualitatif. Berdasarkan fokus penelitian dan cara mendapatkan atau memperlakukan data, penelitian berjenis ini dinamakan sebagai penelitian deskriptif interpretatif. Datadata yang telah terkumpul tidak hanya digambarkan saja melainkan diinterpretasikan. Kegiatan interpretasi melihat dunia pengalaman dan pengetahuan peneliti serta wawasan teoritis yang ditemukan peneliti.
Penelitian ini bertujuan untuk mendapatkan deskriptif objektif tentang hasil struktur naratif dalam novel Tarian Dua Wajah dengan menggunakan pendekatan agamis. Untuk mencapai tujuan itu, data penelitian ini diambil dari seting alamiah berupa novel Tarian Dua Wajah dan peneliti sendiri sebagai instrumen utama.

$$
\text { Pendekatan agamis dalam }
$$
penelitian ini berpandangan bahwa sastra merupakan hasil kreativitas pengarang dengan menggunakan media bahasa yang diabadikan untuk kepentingan estetik. Karya sastra itu sendiri dibangun berdasarkan struktur yang di dalamnya ada sistem agamis, yang antara sistem itu sebagai penopang akan kuatnya struktur itu. Kesatuan itu secara totalitas akan memperkuat sastra bukan hanya berupa kumpulan atau tumpukan halhal atau benda-benda yang berdiri sendiri-sendiri, melainkan hal-hal itu saling terikat, saling berkaitan, dan saling bergantung.

Penelitian spiritual para tokoh dalam karya sastra seperti analisis terhadap novel Tarian Dua Wajah ini 
lebih tepat dan sesuai jika disebut dengan jenis penelitian kualitatif dengan jenis deskripsi.

Peneliti bertindak sebagai instrumen utama (human instrument). Peneliti sebagai instrumen utama berarti kehadiran peneliti bertindak sebagai perencana, pelaksana pengumpulan data, penafsiran data, dan pada akhirnya yang ia menjadi pelapor hasil penelitian (Moleong, 2000:103).

Sumber data dalam penelitian ini yakni teks novel dengan judul Tarian Dua Wajah yang ditulis oleh S. Prasetyo Utomo. Identitas sumber data ialah judul novel Tarian Dua Wajah, pengarang S. Prasetyo Utomo, jumlah halaman 258, penerbit PT Pustaka Alvabet Tangerang Selatan, Cetakan 1 Juni 2016. Novel Tarian Dua Wajah dibagi menjadi beberapa judul, tetapi setiap judul tidak diberi nomor.

Teknik pengumpulan data dalam penelitian ini yakni teknik pustaka, teknik simak, dan catat. Analisis data dalam penelitian ini bersifat kualitatif yang deskriptif. Terdapat tiga jalur analisis data kualitatif, yaitu: reduksi data, penyajian data, dan penarikan simpulan. Analisis data pada penelitian ini menggunakan metode penafsiran data. Metode penafsiran data ini dijabarkan menjadi, (1) tujuan yang diinginkan, (2) prosedur, (3) peranan hubungan unsur lain, (4) peranan kesatuan data, (5) langkahlangkah penafsiran data dengan metode analisis struktural.

\section{HASIL DAN PEMBAHASAN}

Pada bagian ini akan menampilkan tindakan para tokoh cerita sebelum melaksanakan spiritualitasnya. Dari mereka sebagian ada yang berperilaku jahat, seperti: melanggar norma-norma agama dan membunuh. Dalam novel Tarian Dua Wajah akan ditampilkan perilaku sebelum melaksanakan spiritual, yaitu Sukro.

\section{Tokoh Sukro}

Pikiran awal tokoh Sukro sudah dirundung kesedihan. Angan-angannya tertuju kepada nasib yang menimpanya yaitu dia telah menjual tanah warisan yang belum dibayar dengan lunas. Sejak kecil Sukro sudah terbiasa melihat benda tajam seperti pedang, 
ingin rasanya Sukro memegang gagang pedang, tetapi ibunya selalu melarang "Jangan kau hunus pedang pusaka itu. Kelak kalau kau dewasa, boleh menghunusnya!" (hlm.1)

Sukro terlanjur menjual tanah dan sertifikat tanah sudah diterima oleh pembeli hanya saja pembayarannya masih belum lunas. Dalam hati Sukro jiwanya tidak tenang, pikirannya kalut dan ingin urusannya cepat beres. Yang dilakukan Sukro hanya ingin menakut-nakuti si pembeli, agar cepat melunasi pembelian tanah tersebut. Sepertiga pembayaran belum dilunasi masih tertunda. Pahadal istri Sukro sebentar lagi mau melahirkan anak. Istrinya bernama Aya, kandungannya dilihat dokter bayi sungsang dan harus dioperasi butuh dana banyak untuk melahirkan.

Sebetulnya Sukro sudah memberi tenggang waktu satu tahun kepada sang penguasaha itu, sampai menunggu istrinya melahirkan, tetapi jika belum dibayar Sukro nekad dengan menggunakan caranya sendiri. Sepasang pedang pusaka itu terus menggoda ingatan Sukro. Mungkin pedang itu agak sedikit berkarat, tetapi bila diasah akan menjadi berkilau karena pedang itu terbuat dari besi baja. Rasa sayang Sukro kepada istrinya menahan sakit setelah pulang bekerja sebagai penyanyi kelab malam, sehingga dia mendatangi kantor pengusaha tanah tersebut.

Sukro masih menahan diri untuk tidak marah walaupun pengusaha itu tampak sinis dan mengabaikan kedatangan dirinya. Sukro selalu memohon dengan harapan luluh hati sang pengusaha tersebut, tetapi justru sebaliknya Sukro dihina dan istrinya juga disangkutpautkan dengan pekerjaannya. Emosi Sukro tambah meletup-letul. Hal itu dapat dilihat dalam kutipan berikut ini.

"Aku hanya menagih hakku."

"Aku juga mempertahankan martabatku. Aku tak bias kau peras serupa ini."

Apa kau tak menaruh iba dengan keselamatan istri dan anakku?"

"Iba? Istri macam apa dia, hingga aku mesti menaruh rasa iba? Penyanyi kelab malam dan siapapun tahu, dia bisa dinikmati lelaki berduit manapun!” (hlm.6).

Pulang dengan tangan hampa tanpa membawa uang dari sang pengusaha itu, Sukroo merasa hatinya 
sakit karena mendapatkan hinaan dan cacian. Sukro lalu teringat salah satu pedang yang tergantung di dinding kamar pusaka. Ketika memasuki kamar tua yang penuh pusaka, dia mengambil salah satu pedang yang tergantung di dinding lalu ditariknya gagang pedang yang masih kukuh. Tangan Sukro bergetar seperti ada setrum yang mengalir ke tangan, lalu dia pergi ke belakang rumah mengambil batu asah lalu digosokgosokkan. Dengan hati-hati penuh semangat pedang itu diasah hingga warnanya berubah menjadi mengkilat.

Sukro teringat wajah istrinya yang kesakitan belum ada biaya dan teringat wajah pengusaha yang sinis dan menghina istrinya, terus Sukro mengasah pedang lalu melakukan gerakan-gerakan tangan yang teratur ibarat gerakan tangan menebas leher orang. Pedang itu yang menggerakkan tangan Sukro, bukan Sukro yang menggerakkan pedang itu. Tangan Sukro tidak lagi bergetar, dia sudah tenang jiwanya dan sebilah pedang sudah berada ditangannya. Sebelum meninggalkan rumah tua, Sukro sempat memandangi lukisan Nyai
Laras dan Kiai Jagkung yang ada tulisannya di ruangan tamu. Tekadnya sudah bulat pergi ke rumah pengusaha yang membeli tanah bukit, tetapi belum dibayar secara lunas. Kedatangan Sukro ke rumah pengusaha bukan semata-mata menangih, tetapi dia ingin membalas atas cemoohan kepada Aya, istrinya Sukro, hal itu dapat dilihat dalam kutipan berikut ini.

... Kali ini ia kembali ingin mendatangi sang pengusaha, bukan semata-mata untuk menagih uang. Yang lebih penting, ia mesti membalas penghinaan lelaki setengah baya itu terhadap istrinya yang bertaruh nyawa di rumah sakit, menanti kelahiran anak pertama (hlm.9).

Kedatangan Sukro tepat tengah malam di rumah sang pengusaha, sehingga mengagetkan satpam yang sedang berjaga di rumah sang pengusaha. Dengan perangai dam perilaku Sukro yang agak sedikit penakutkan satpam tersebut mengikuti kemauan Sukro.

Kejadian di dalam rumah, Sukro hanya mengambil uang dan perhiasan sebagai pelunasan atas pembelian tanah bukit yang belum dibayar secara lunas. Sukro berjanji jika uang dan 
perhiasan yang dibawah Sukro terlalu banyak akan dikembalikan. Tampaknya kejadian di dalam rumah tidak memberikan kesadaran pada diri sang pengusaha, sehingga ketika tangan Sukro mengambil uang dan perhiasan, kesempatan itu digunakan oleh sang pengusaha untuk memukul Sukro hingga jatuh. Hal itu dapat dilihat dalam kutipan berikut ini.

... Ia meraup uang dan segenggam perhiasan, memasukkan ke dalam saku celananya. Kelengahan ini digunakan sang pengusaha untuk memukul muka Sukro. Keras. Telak. Terjatuh.

Meraih pedang pusaka dengan kesadaran yang hilang, membangkitkan kemarahan Sukro tak terkendali. Pedang pusaka itu mengusai kesadaran Sukro, Tak terkendali, tangannya mengayunkan pedang, berkelebat, menebas leher sang pengusaha (hlm.11)

Akhirnya, Sukro membunuh sang pengusaha, dia berani beresiko untuk menanggung semua perbuatannya. Di sisi lain, ada kebahagiaan di hati Sukro sebelum ditangkap polisi di rumah sakit. Dia telah melihat bayi mungil telah lahir dan istrinya dalam keadaan sehat, dia berpesan dengan sangat pelan hampir Aya tidak mendengar.
Pakde Rustam dan Aji datang dari Jakarta menuju penjara untuk menemui adiknya dan memperlihatkan anak Sukro agar ada sedikit kebahagiaan pada diri Sukro. Selama di dalam penjara Sukro sempat menggendong dan menciumi anaknya.

Setelah pulang dari penjara Aji mendapatkan kesan laki-laki yang di dalam penjara wajahnya mirip Pakde Rustam, seseorang yang tidak terkesan jahat, keji, atau beringas hanya tatapan matanya agak tajam, tetapi orang tersebut tidak menakutkan sama sekali.

Sukro melarikan diri dari penjara padahal hukuman Sukro sudah 15 tahun, kurang 2 tahun lagi dia bebas dan menjadi manusi bebas. Apa yang dilakukan Sukro sangat membahayakan sekali bias-bisa ditembak dan jika lolos dari penjara harus berenang, jika nafasnya tidak kuat bias-bisa mati di tengah laut.

Pelarian Sukro dari penjara bukan tidak diketahui oleh para sipir penjara, tetapi para sipir mengejar ke hutan. Sukro bersembunyi di gua yang lembab berlumut dan dingin. Udara yang dingin membuat Sukro 
meringkuk dan kegelapan dalam keadaan haus dan lapar. Ada keraguhan dalam hati Sukro bias sampai pantai dengan selamat atau justru sebaliknya ditembak mati oleh sipir penjara.

Rasa bosan bertahun-tahun berada di dalam penjara sangat membosankan

Sukro. Oleh karena itu, niat yang kuat bertemu dengan anaknya apapun dilakukan.

Tak ada lagi rasa takut. Kalupun mati, tertembak atau tenggelam dalam laut, Sukro tak peduli lagi. Ia ingin mengakhiri hidup dalam pengasingan. Penjara senantiasa menyekapnya dengan udara yang sama: pengap, lembab. Membosankan. Ia tak lagi merasakan hangat matahari.... (hlm.8687).

Di dalam gua yang dingin dan gelap Sukro menemukan suasana lain, dia puas membayangkan wajah anaknya yang bernam Aji. Jika sudah bertemu Sukro ingin minta maaf.

.... Dalam gelap, ia merasakan degup dadanya sendiri. Ia bias membayangkan wajah Aji, anaklelakinya. Ia berharap bertemu dengan anak lelaki itu. Ia ingin memeluknya, memohon ampun. "maafkan ayakmu, Nak. Kau bukan keturunan perampok dan pembunuh. Kau keturunan Nyai Laras, penari keratin yang hidup terhormat di tengah masyarakat." (hlm.87).

Sudah tiga hari Sukro berada di dalam gua sambil menunggu senja tiba di tepi pantai lalu dia mau menyusup ke hutan bakau. Di pastikan para sipiur penjara yang bersenapan betul-betul tidak mengepung lagi. Sudah benarbenar disadari bahwa waktu 15 tahun Sukro merasakan kehinaan dalam penjara. Padahal dua tahun lagi dia akan keluar bahkan mungkin kurang dari dua tahun apabila kelakuannya baik. Dia ingin bebas memurut keinginannya sendiri dan dia tidak ingin di kekang oleh siapapun. Keinginannya sudah bulat perut lapar dan haus dalam gua tidak membuat Sukro sedih.

Senja hari Sukro menemukan tekad menceburkan diri ke laut lalu berenang menuju pulau Jawa yang baginya member harapan hidup. Sukro menelusuri pohon bakau yang perdu dengan rimbun lalu terdengar tembakan beruntun di sekitar tubuh Sukro "Dia lari ke pantai (hlm.89). Sukro mendekam berdiam diri di sisi batang pohon bakau yang rimbun sekali. Tanpa ada sesuatu yang mencurikan sipir penjara. Malam tiba Sukro berenang tanpa disadari ada seekor buaya yang mengikuti lalu kaki kanannya digigit. Darah memancar 
hingga hitam air laut. Sukro berteriak kesakitan sehingga seorang nelayan yang berangkat malam dating dan menolong di bawah ke rumah sang nelayan.

Ketika Sukro membuka mata, dia sudah berada di gubuk nelayan dengan ditemani anak kecil, sambil sang nelayan berkata.

"Semalam kau mengigau, memanggil-manggil nama anakmu," kata nelayan. "Aku sudah mengobati lukamu dengan ramuan dedaunan petai cina. Mudah- mudahan lekas mongering. Tinggallah di sini samapai lukamu sembuh.” (hlm.91).

Di tempat rumah nelayan yang miskin itu, Sukro dibuatkan kruk oleh nelayan hingga Sukro diajari cara berjalan sampai kaki kanannya kering. Setelah itu, Sukro pamit pergi meninggalkan nelayan tengah malam. Dengan tertatih-tatih Sukro pergi mengembara mencari anaknya bernama Aji. Hati Sukro merasa bersalah telah membiarkan anak lelakinya itu tidak merasa kasih sayang.

Sungguh sayang yang akan ditemui yaitu Aji sudah pergi menuju pesantren Kiai Sodik. Sukro hanya bertemu dengan kakaknya Rustam.
Sukro menyusul ke pesantren Kiai Sodik di sana juga tidak ditemukan keberadaan Aji. Tubuh sukro bergetar dan dia sambil berdzikir dalam tangis terisak-isak sampai fajar tiba. Kiai Sodik dihadapan Sukro lalu mengutarakan keinginannya.

"Saya ayah Aji, Kiai. Saya ingin bertemu anak saya," suara Sukro tergetar, dalam sekali getaran itu, dari relung jiwa.

"Saya memang mengundang kau ke sini."

"Ke mana anak saya? Saya ingin ketemu."

"Dia mencarimu di pulau pengasingan.”

Sukro terbelalak. Ingin beranjak bangkit.

"Aku membiarkannya pergi, agar kalian tak bertemu. Aku tak ingin perasaannya guncang. Memang kalian belum waktunya bertemu."

"Kenapa, Kiai?"

"Biar di tumbuh dengan dirinya sendiri. Biar dia jadi lelaki tangguh. Nanti, akan tiba saatnya, kalian pasti akan bertemu (hlm.92-93).

Sukro masih ingin berada di masjid, tetapi mobil penjara telah menunggu di luar. Sukro sempat tergeragap setelah lelaki berseragam, berambut cepak, bersenapan, memegang lengan Sukro, tetapi dia sempat berpesan kepada Kiai Sodik.

"Kiai, titip anak lelaki saya," Kata Sukro memohon, tenang. 
"Biar dia di sini bersamaku. Kau tak perlu cemas." (hlm.93).

Kini, Sukro tidak muak melihat wajah sipir lagi, dia tidak membenci sipir penjara yang akan ditemuinya tidak lama lagi, sebab dia sudah mengetahui jati diri anaknya Aji. Aji telah menemukan tempat berlindung yang baik tidak seperti bapaknya yang mempunyai masa lalu yang kelam.

Setelah bebas dari penjara, Sukro mendatangi makam Nyai Laras. Barangkali merupakan kemujizatan tersendiri, di sana Sukro bias bertemu dengan Aji di tempat pekuburan Nyaoi Laras. Hal itu pelarian dari penjara juga diceritakan kepada Aji. Setelah bercerita banyak Sukro turun bukit dan dibawa dihadang oleh preman tukang parkir. Dalam keadaan cacat, Sukro dihajar dan ditendang hingga babak belur lalu dia ditolong mandor Karso di bawa ke rumah tua. Setelah melihat kamar pusaka Sukro mengambil lalu mengasahnya pedang tersebut yang akan digunakan untuk membunuh wajah preman yang menyakitinya.

Rasa dendam Sukro ingin membalas kepada preman parker itu, sebelum tengah malam tiba, Sukro masih sempat di warung angkringan minum wedang jahe saja tidak makan nasi seperti biasa. Tiba tengah malam Sukro meninggalkan warung angkringan menuju ujung jalan tempat rumah preman parker yang telah menghajarnya. Sukro menantang kepada preman parkir tersebut dan setelah preman parker keluar langsung ditebasnya leher hingga meninggal. Setelah membunuh preman parkir itu, pagi hari Sukro ditangkap polisi.

"Kau kira kau bisa merendahkanku dengan cara sesukamu!" kata Sukro, tepat berdiri di depan lelaki beringas dengan luka bacok di pipi kiri.

"Kau menantangku?" hardik lelaki beringas dengan luka bacok di pipi kiri.

"Apa yang akan kau lakukan lelaki buntung?"

Tangan kiri Sukro mengangkat pedang pendek diayunkan, menebas leher lelaki dengan luka bacok di pipi kiri. Lelaki itu rubuh seketika ... (hlm.124-125).

\section{Kondisi tokoh Sukro sesudah melakukan spiritual (tinggal di pesantren Kiai Jangkung)}

Sukro bebas dari penjara, dia masih ingat pernah ditolong oleh seorang nelayan ketika melarikan diri dari penjara dan kaki kanannya digigit buaya. Di temapt nelayan, Sukro 
tinggal hingga lukanya sembuh lalu Sukro dibuatkan kruk oleh nelayan tersebut.

Ingatannya tidak bisa lupa atas jasa baik sang nelayan tersebut. Kini, Sukro menengok ke rumah nelayan miskin itu, Sukro agak heran bukan karena di dalam rumah tidak mempunyai apa-apa, tetapi nelayan itu terkena stroke. Dalam hati Sukro harus menolong nelayan itu. Hal itu sebagai timbalebalik, karena dulu Sukro pun pernah ditolong olehnya.

Hal serupa juga sama Sukro membuatkan kruk untuk latihan berjalan. Pada sore hari mereka berjalan keliling kampong bersama. Tiga hari Sukro berada di rumah nelayan miskin lalu dia minta izin untuk melanjutkan perjalanan menuju kampung halaman. Akan tetapi, sungguh aneh ketika sampai di pesantren Kiai Sodik, Sukro tidak berani masuk dia malah menuju ke lembah bukit. Di sana ada pesantren milik Kiai Jangkung yang sudah lama ditinggalkan para santri. Di sana Sukro bertemu denga anak muda yang selalu menjadi imam masjid. Didapatinya anak muda itu masih sakit karena jatuh dari kuda putih milik almarhum ayahnya. Sukro berusaha menyembuhkan anak muda itu dengan cara memijatnya sampai sembuh. Setiap malam Sukro pergi menawarkan jasa memijat kepada masyarakat. Selama menjadi tukang pijat keliling, Sukro tidak berani mampir ke rumah anaknya Aji. Sukro tidak bergantung kepada Aji (anaknya), dia sungguh mandiri dan tidak mengemis, tetapi dia menjual jasa dan menolong orang lain dengan keahliannya. Barulah di ingat pedang pusaka yang digunakan untuk membunuh belum diambil di kepolisian, dia mampir ke rumah Aji dengan sambil berpeasan kepada menantu Salma "Kalau suatu saat datang seseorang menyerahkan sepasang pedang pusaka kemari, terimalah!” pesan Sukro. Letakkan kedua pedang pusaka itu di dinding kosong ini!” (hlm.252)

Di tempat pemakaman Aya, istrinya Sukro bertemu dengan Aji dan orang yang tinggal di sekelilingnya makam. Setelah usai pemakaman sebelum Aji meminta kepada Ayahnya, Sukro tahu diri bahwa 
dirinya mempunyai masa lalu yang tidak baik sehingga dia tidak pantas tinggal serumah dengan anaknya. Saat itu juga Sukro minta izin kepada Aji mau kembali ke pesantren milik Kiai Jangkung (almarhum) di sana lebih sepi untuk merenungi dosa-dosa yang pernah dilakukan Sukro.

\section{SIMPULAN}

Dengan terpaksa Sukro membunuh sang pengusaha, dia berani beresiko untuk menanggung semua perbuatannya. Di sisi lain, ada kebahagiaan di hati Sukro sebelum ditangkap polisi di rumah sakit. Dia telah melihat bayi mungil telah lahir dan istrinya dalam keadaan sehat, tetapi Sukro tidak lama ditangkap polisi. Dan dihukum selama 15 tahun. Belum sempat 15 atahun dia sempat kabur dari penjara, sehingga membuatnya dia kehilangan kaki kanannya karena dimakan buaya.

Ia bertobal dengan caranya sendiri. Ia sholat dan berdzikir di makam Nyai Laras.

\section{DAFTAR PUSTAKA}

Ahmad D. Marimba, op. cit. 1992. Achmadi, Islam Sebagai Paradigma Ilmu Pendidikan. Yogyakarta: Aditya media.

Abdurrahman An Nahlawi. 1995. Pendidikan Islam di Rumah, Sekolah dan masyarakat. Jakarta: Gema Insani Press.

Alwisol. (2005) Psikologi Kepribadian. Malang: Universitas Muhammadyah Malang.

Aminuddin, 1991. Pengantar Apresiasi Sastra. Bandung: Sinar Baru dan Malang: Yayasan Asah-Asih-Asuh.

---------------. 1987. Karya Sastra sebagai Gejala Komunikasi Khas Berupa Bahasa. Malang: JPBSI IKIP 1990. Sekitar Masalah Sastra. Malang: Yayasan Asih Asah Asuh

Arikunto, Suharsimi. 2006. Prosedur Penelitian Suatu Pendekatan Praktik. Jakarta: Rieneka Damono, Sapardi Djoko. 1978. Sosiologi Sastra: Sebuah Pengantar. Jakarta: Gramedia.

Frederick J. MC. Donald, 1959. Educational Psychology. Tokyo: Overseas Publication LTD.

H. Titus, M.S, et al. 1984. Persoalanpersoalan Filsafat. Jakarta: Bulan Bintang. 
HM. Arifin, Hubungan Timbal Balik Pendidikan Agama, (Jakarta : Bulan Bintang, 1976) hlm.12

Nurgianto, Burhan. 2002. Teori Pengkajian Fiksi. Yogyakarta: Gadjah Mada University Press.

Miles, M.B. dan Huberman, A. 1992. Analisis Data Kualitatif (terj. Tjetjep Rohendi Rohidi). Jakarta: UI Press.

Moleong, Lexy J. 2002. Metodologi Penelitian Kualitatif. Bandung: PT Remaja Rosdakarya.

Nasional.

Paz, Octavio. 1997. Levi-Strauss Empu Antropologi Struktural terj. Landung Simatupang. Yogyakarta: Penerbit LKis.

Rahmanto, B \& Hariyanto, P. 1997. Materi Pokok Cerita Rekaan dan Drama. Jakarta: Universitas Terbuka

Ratna, Nyoman Kuntha. 2004. Teori, Metode dan Teknik Penelitian Sastra. Yogyakarta: Pustaka Pelajar.

Soegarda Poerbakawatja, et. al. 1981. Ensiklopedi Pendidikan, Jakarta : Gunung Agung.

Scholes, Robert. 1977. Structuralism in Literature. New Haven and London: Yale University Press.

Sudjiman, Panuti. 1990. Kamus Istilah Sastra. Jakarta: PT Gramedia.

Sugiyono. 2007. Memahami Penelitian Kualitatif. Bandung: Penerbit

Alfabeta.
Teew, A. 1988. Sastra dan Ilmu Sastra. Jakarta: Penerbit Giri Mukti.

Wiyatmi. 2006. Pengantar Kajian Sastra. Yogyakarta: Penerbit Pustaka Pelajar

Wellek, Rene \& Austin Warren. 1993. Teori Kesusasteraan. Jakarta: PT Gramedia Pustaka Utama 